\title{
Questões Sociais Existenciais, Tendências de Desenvolvimento e Modernidade
}

\author{
José Maurício Domingues
}

Instituto de Estudos Sociais e Políticos (IESP) da Universidade do Estado do Rio de Janeiro (UERJ). Rio de Janeiro, RJ, Brasil. E-mail: jmdomingues@iesp.uerj.br

\section{O PROBLEMA}

$\mathrm{O}$ objetivo deste artigo é retornar a alguns temas clássicos, centrais no passado da Sociologia ou daqueles que por ela foram incorporados como seus pais fundadores e hoje, a rigor, abandonados. Nele se discutem a multidimensionalidade da vida social e as tendências de desenvolvimento que, em particular na modernidade, a impulsionam. Teoricamente esses temas seguem, ou deveriam seguir, sendo decisivos, sem deixar de sê-lo igualmente do ponto de vista da prática social. Enfim, recolocá-los nos permite até certo ponto sugerir uma visão mais complexa, menos etnocêntrica, da humanidade em seus aspectos diretamente sociais e, com isso, situar mais precisamente as características diferenciais da própria modernidade.

O tema da multidimensionalidade da vida social - ou, mais tecnicamente, dos sistemas sociais - tem sido recorrente nas Ciências Sociais desde ao menos a crítica de Max Weber ao marxismo e sua brilhante e unilateral definição da vida material como vetor causal principal no desdobramento das relações sociais. Entretanto, é forçoso dizer que as soluções propostas para esse imbróglio dificilmente são adequadas. A maior parte delas, mesmo quando sugerida sob uma roupagem supostamente analítica ou ao menos conceitualmente genérica, é meramente

DADOS - Revista de Ciências Sociais, Rio de Janeiro, vol. 59, non 1, 2016, pp. 203 a 231. 
descritiva. Quando conceitualmente articuladas, as soluções deixam muito a desejar.

É verdade, por exemplo, que Alexander (1988: cap. 1), com perspectiva neoparsoniana, pôs o tema do ponto de vista da "ação", com seus elementos normativos e condicionais, mas não foi muito mais longe que isso, sem tocar os sistemas sociais e depois, de resto, abraçando um forte idealismo cultural. Mann (1986), por seu turno, tentou solução própria e inovadora com suas "redes do poder social", de clara inspiração weberiana, mas o resultado é discutível, deslizando rumo a um conceito, por vezes de maneira pouco consistente reivindicado como "tipo ideal", descritivo e redutivo, isto é, pouco teorizado e concentrado no tema do poder, excessivamente generalizado. Com mais frequência fala-se em "economia", "política" (também "polity" ou, mais recentemente, "o político"), "cultura" (ou "ideologia") etc. (aliás, eu mesmo o fiz, embora frisando que se tratava de solução provisória para problema de difícil resolução, em Domingues, 2008). Ou então, a referência é a sistemas específicos, como o Estado, a família, a religião. Em geral, se trata de respostas dadas em um plano muito concreto, inclusive quando se supõe que fortes teorizações se apresentam, como "mundo da vida" unitário e sistemas autorregulados da economia e da política no neoevolucionismo de Habermas (1981).

É necessário, assim, revisar os próprios fundamentos desse tipo de afirmação generalizante. De início, porém, note-se que o risco que se corre ao embarcar numa rejeição de conceitos gerais é o de cair-se em um nominalismo crasso, que demandaria conceitos muito localizados (talvez derivados de alguma forma de "descrição densa" que se esgotaria em si) e recusaria universalismos teóricos, com grau variado de radicalidade. Não é este evidentemente o objetivo que se persegue aqui. Se busco uma abordagem e um nível de generalidade que evite a hipostasiação de certos conceitos nos moldes daquilo que são características apenas da civilização moderna, o que pretendo é levá-la a um plano de universalidade que é ao mesmo tempo pressuposto e resultado de investigações mais concretas, embora valha sublinhar que não há repouso definitivo para a pesquisa e os resultados teóricos que dela resultam. Um vai-e-vem interminável é o que se deve esperar. Isso implica conceitos, em qualquer nível de generalidade, sempre cambiantes, assim como, por outro lado, a própria definição do que são os fenômenos empíricos se alterando à medida que muda a teoria. 
Como veremos, as melhores soluções, ou ao menos as melhores maneiras de pôr a pergunta, encontram-se a meu ver ainda nos trabalhos de Marx e Engels, por um lado, e, por outro, de Weber. Eles ainda fornecem pistas conceituais gerais bem como específicas, além de um acervo de importantíssimas investigações sobre os temas que quero aqui colocar em tela. Aqueles dois primeiros delinearam pressupostos gerais da vida social que, se presos de fato a um reducionismo em que o materialismo remete sobretudo a uma relação com a natureza que afeta em primeiro lugar as bases orgânicas da vida por meio do trabalho, ao menos apontam para temas que todos os indivíduos e coletividades têm inevitavelmente de responder, sem definir a priori a maneira como essa resposta se articula em termos de sistemas sociais concretos e específicos. Já Weber (1904:45), depois de criticar o "sentido primitivo genial" do materialismo histórico (mais genial que primitivo, deve-se dizer, ainda que redutivo), não chega a pôr-se explicitamente aquela indagação, mas a responde, ao longo de sua obra, através de uma análise extremamente sofisticada e variada de sua evolução histórica, assinalando as diversas respostas que as coletividades humanas forneceram às questões que lhes são inevitavelmente postas, em quaisquer coordenadas espaço-temporais (embora se deva sublinhar a manobra unificadora, porém demasiado simplificadora, de ao fim e ao cabo enfeixar todas as "esferas" da vida social na modernidade mediante o conceito de racionalização instrumental - ver em especial Weber, 1920a) ${ }^{1}$. Em contrapartida, a ideia de questões sociais existenciais, articulada analiticamente e de modo a abrigar variadas concretizações históricas, nos permitirá em princípio tratar da multidimensionalidade de maneira efetiva, sistemática e flexível.

Além de ser um problema por si só de máxima importância, situado no núcleo fundamental das Ciências Sociais e, ainda mais amplamente, Humanas, uma alternativa que avance em relação às costumeiras soluções descritivas e concretas ajuda essencialmente no sentido de delinear o que se poderia chamar de tendências históricas - e mesmo evolutivas - de desenvolvimento da vida social (Domingues, 2014). É crucial em particular para recolocar de maneira inovadora e relevante, inclusive do ponto de vista de possíveis processos de transformação social, as tendências de desenvolvimento que levaram à modernidade e à modernização do planeta. Isso se aplica àquelas que se desdobram dentro dela, bem como às que remetem à sua possível superação, sem que nos aferremos aos sistemas concretos focalizados pela maioria dos autores, teóricos ou não, das Ciências Sociais. Enfim, trata-se de com- 
preender esse processo também em termos do que se pode chamar de multitendencialidade.

Vale frisar que o cruzamento aqui proposto entre questões existenciais e tendências de desenvolvimento não é em absoluto arbitrário. Essas questões são respondidas socialmente apenas de maneiras específicas. Ou seja, dependem de como se articulam em cada civilização ou cada "formação social". Tampouco são estáticas: sua articulação se desdobra historicamente, ainda que em cada civilização e formação social mantenham padrões que se reiteram na longa duração da história. Esse é o caso da modernidade e é em relação a ela que mais adiante discutiremos com certo detalhe a questão dos conceitos capazes de identificar e apreender conceitualmente suas múltiplas tendências de desenvolvimento.

\section{AS QUESTÕES SOCIAIS EXISTENCIAIS}

Uma das afirmações-chave de Marx e Engels (1845:18-36 e ss) em um dos textos fundadores do "materialismo histórico", a coleção de fragmentos inéditos que veio, editorialmente já em várias versões, a constituir A ideologia alemã, era de que os seres humanos precisam produzir e reproduzir sua vida como tarefa básica e fundamental. Isso queria dizer que havia dois elementos prioritários em suas atividades. Primeiramente, tratava-se da reprodução da espécie, da sucessão de gerações (através da sexualidade, não diretamente nomeada no texto), com a transformação dos infantes em membros plenos das coletividades (outro tema deixado implícito, com a família ademais universalizada de modo equivocado como a base dessa reprodução). Em segundo lugar, referiam-se à produção material, que transforma a natureza mediante o trabalho e nos permite dela nos apropriarmos, consumindo-a para sustentar diretamente a vida e ao mesmo tempo produzindo os meios com os quais é possível dar sequência à produção².

Mais que isso, esses elementos seriam ontologicamente mais fundamentais que quaisquer outras atividades. Eles corresponderiam à própria emergência da espécie humana e possibilitariam a sua existência, com muito mais ênfase dada à própria transformação da natureza (mencionada, aliás, com foros de exclusividade nas primeiras páginas do manuscrito) no argumento desses autores, embora digam igualmente que se encontram combinados concretamente esses três "lados" (Seiten) da vida social - ou "momentos", palavra necessária para o en- 
tendimento dos filósofos alemães, segundo dizem jocosamente. A partir dessas atividades se constituiria nosso "ser social" e, em lugar de ser a "consciência" (Bewusstsein) o que determinava essa existência, era esta que determinava aquela. Ela seria não mais que o ser consciente (bewusst Sein), segundo o jogo de palavras em alemão que os autores propunham. Trata-se de intuição seminal, embora com antecedentes fortes em correntes econômicas e filosóficas que vão da economia política clássica ao idealismo alemão.

Dada a genialidade dos autores, é intrigante até certo ponto que tenham optado por uma visão tão redutiva, o que se explica pelo contexto do debate contra o idealismo (malgrado isso tenha sido reiterado em textos posteriores de forma bastante explícita) e pela excitação intelectual que tal intuição "materialista" certamente lhes suscitava, ao descortinar todo um novo campo de análise, que, ao fim e ao cabo, remetia às lutas de classe sob o capitalismo. Fato é, contudo, que deixaram de lado a produção de sentido, hermenêutico-simbólica - embora assinalem o papel crucial da linguagem -, e a distribuição de poder que são características da própria espécie. Ou melhor, trataram-nas, desde esse momento, como derivadas causalmente dos processos "materiais" que identificaram como sendo ontologicamente anteriores àqueles outros, como parte, diria Marx (1859) mais tarde, da "superestrutura" que se ergue sobre a base econômica (como ideologia e estado, embora o poder mesmo em sua obra aparecesse de forma mais ampla, a começar pela "infraestrutura").

Não necessitamos copiar esses equívocos, que pertencem a um tempo em que as Ciências Sociais apenas engatinhavam, na verdade eram em larga medida fundadas por Marx e Engels eles mesmos (como "ciência da história", diria Althusser, 1965), especificamente naqueles volumes cuja publicação se fez, porém, apenas de modo póstumo e bastante tardio. Em sua "reconstrução do materialismo histórico", Habermas (1976), entre outros, chamou atenção para o tema de maneira direta, embora sua solução cognitivista e moral, bem como dualista, seja deficiente. Mas a identificação de questões que dizem respeito à exata existência da espécie humana, através das quais ela se reproduz como espécie, é intuição conceitual de enorme alcance. É ela precisamente que quero adotar, de modo a avançar na direção de obter mais flexibilidade teórica, ao transplantar o tema da multidimensionalidade a um plano mais geral, por ora em parte abstrato, pois carente de conteúdo preciso. Isso deve ser feito, é evidente a esta altura do texto e da história das 
Ciências Sociais, incluindo, mas indo além das questões que Marx e Engels colocaram no cerne de sua concepção materialista da história. Isso nos leva assim a abraçar os dois outros elementos acima mencionados, quais sejam, a confecção de teias de sentido e as tramas do poder, que vieram a ocupar lugar de destaque nas Ciências Sociais de forma sistemática desde a obra de Weber.

O conceito de questões sociais existenciais se apresenta aqui precisamente com o papel de permitir que nos ponhamos em uma situação de mais generalidade, anterior conceitualmente à definição concreta das respostas aos requerimentos fundamentais, ontológicos, da existência humana. Isto é, viso uma maneira de deixar de lado aquelas dimensões da economia, da política, da cultura etc., em sua faticidade concreta, recuando a um plano em que se possa alcançar uma teorização mais flexível e inovadora ${ }^{3}$. Basicamente suponho, seguindo a inspiração de Marx e Engels, que há temas que as coletividades humanas não podem deixar de enfrentar como espécie, ao passo que identifico, para além da produção e reprodução, outros dois, o poder e a construção de sentido hermenêutico-simbólica. Quero sublinhar ademais que a reprodução deve se abrir para a questão da sexualidade, que somente após Marx e Engels se pôs mais centralmente para o pensamento social (Freud sendo a maior expressão científica e cultural da ênfase nessa questão, mas de modo algum a única) e que a produção do sentido está intimamente ligada à própria produção da linguagem, conquanto as práticas apenas parcialmente sejam determinadas por elas (se é legítimo utilizar a expressão "jogos de linguagem" para nos referirmos a elas, vale frisar que estes são antes de tudo jogos). A produção de sentido conforma, enfim, um imaginário, cambiante, "magmático", tal qual observado por Castoriadis (1975; ver também Domingues, 1999:cap. 2), que assim oferece conceito muito mais preciso que o usual de "cultura", em suas diversas acepções ${ }^{4}$. Enfim, o poder supõe, em muitas circunstâncias, a força, capacidade de coerção física ou de qualquer outro tipo, como desde Hobbes ao menos se sabe bem. Refere-se todavia, acima de tudo, à "capacidade transformativa" dos seres humanos, de produzir resultados, individual e coletivamente, o que pode incluir a capacidade de fazer com que outrem faça aquilo que o agente quer que ele ou ela faça. Engendra assim inclusive sistemas de dominação, com a distribuição desigual, socialmente, de exercer aquela capacidade (Weber, 1921-1922:28-29; Parsons, 1967:caps. 10-11; Giddens, 1984:14-16) ${ }^{5}$.

Em suma, independentemente de como se organize, de onde viva e em que era, a espécie humana tem de enfrentar quatro questões que são 
inevitáveis e em sua conjunção a definem inclusive como espécie. Deve-se notar, a bem da verdade, que essas questões elas mesmas aparecem em sua separação apenas no discurso conceitual, pois na realidade há muitos pontos de entrelaçamento entre elas. Não há produção ou reprodução sem universo simbólico nem sem estruturação do poder, nem deste ou daquele sem bases materiais, ao passo que poder e sentido não podem senão caminhar juntos, sejam quais forem as formas e os conteúdos específicos que assumam ${ }^{6}$.

Deste modo, podemos descartar, por ora ao menos, os conceitos descritivos e concretos de economia, sociedade, cultura etc. Por ora ao menos porque, de certo modo, será necessário retornar a eles e reintroduzi-los no quadro conceitual ao focarmos diretamente a modernidade, juntamente com outros, mais precisos, de Estado, capitalismo, família etc., uma vez que eles são com efeito elementos salientes de como a espécie humana veio a se organizar nos quadros dessa civilização.

Mobilizei até aqui Marx e Engels para delinear essas questões sociais existenciais, apesar de minha crítica e do primeiro, em texto com frequência citado, ter assinalado a necessidade de não estruturar o pensamento a partir de questões abstratas, que aqui são, seja como for, apresentadas de maneira apenas parcialmente abstrata, na medida em que, ao recobrirem os requerimentos ontológicos básicos da vida humana, fazem-se em certa medida concretas. Na famosa introdução aos Grundrisse, Marx (1857) sugeriu que uma exposição categorial sistemática do modo de produção capitalista, que veio a realizar em O Capital, não deveria partir de questões gerais, como a divisão do trabalho, mas do desenvolvimento completo das categorias, na situação específica do mundo moderno, para que se pudesse fugir de generalidades típicas da filosofia da história. Em grande medida isso tem sentido, embora se deva relativizar a afirmação e observar que Marx levou muito tempo até decidir o formato final de sua obra-mestra, além de estabelecer certo tipo de anacronismo ao supor que o que ocorre na modernidade seja a chave para a "anatomia" de todas as formas sociais anteriores (assim como o homem o seria em relação ao macaco). Mas do ponto de vista de uma elaboração ampla, sociológica e historicamente orientada, é a Weber que temos de recorrer. Essas questões existenciais são trabalhadas em seus textos, sobretudo no que são os diversos esboços reunidos no que acabou por ser conhecido como Economia e Sociedade (1921-1922), embora saibamos hoje que esses volumes, editados por sua esposa, não possuem a organicidade que um dia se imaginou. 
Weber trata de todas essas questões em muitos aspectos. A sexualidade e a reprodução geracional, o poder, a economia e o universo hermenêutico-simbólico, assim como aspectos mais concretos do funcionamento dos sistemas sociais, que incluem a família e a organização dos gêneros, o capitalismo, as igrejas, a religião e o Estado, outras formas de "dominação" e o direito, assim como muitos outros elementos mais específicos comparecem a Economia e Sociedade e a suas outras obras, embora naquela, curiosamente e apesar do título, em simétrica oposição em relação a O Capital de Marx, as seções sobre economia sejam de fato as menos interessantes.

Tomemos as conhecidas formas de "dominação legítima" - tradicional, carismática e racional-legal -, que na versão oficial daquele volume de síntese tinham como seguimento (e decerto no pensamento de Weber era este de toda maneira o caso, ver Domingues, 2000) a forma "ilegítima" de dominação que encontrava na cidade medieval sua recusa, com uma situação de liberdade de seus cidadãos. Sob a definição dessas formas de dominação, absolutamente centrais em sua obra, Weber (1921-1922:122-182; 541-868) inclui as relações entre homens e mulheres, velhos e jovens, patrões e empregados, guerreiros e camponeses, monopolizadores da religião e controladores da definição política das normas e comportamentos sociais. Mas é somente ao referir-se à modernidade que define a forma de dominação mais geral como calcada no "Estado". Este monopoliza os "meios legítimos de violência" em um território determinado e circunscrito (isto é, exerce "soberania" nele), além de funcionar de acordo com normas gerais e abstratas e contar com uma burocracia separada de si mesmo por não pertencerem aos funcionários os "meios da administração" (formulação claramente inspirada na definição de Marx das classes trabalhadoras modernas). Weber não se refere ao "Estado" em outras circunstâncias - o que não significa que, no que concerne a outras formações sociais históricas, isso não pudesse ser correto, vale dizer claramente, em parte na contramão de suas concepções -, mas sim àquelas outras maneiras de distribuir e organizar o poder, inclusive ao falar da democracia da cidade e sua liberdade, que se estabeleceram contra a dominação e finalmente pereceram frente ao crescimento do Estado absolutista. Ademais, as formas de dominação atravessam todos os âmbitos da vida social, mesmo na modernidade, penetrando, por exemplo, a empresa capitalista racional moderna, conquanto no que toca aos gêneros ele não articule o tema de maneira clara (no que a ideia de direito racional decerto ajudaria). 
Seria interessante se Weber tivesse feito o mesmo no que tange à "religião", área fundamental e carregada de ideias luminosas em sua obra", com a limitação, todavia, de não haver ao menos problematizado uma definição tão ocidental e moderna como essa. Poderia haver buscado a configuração do pensamento e da espiritualidade, das crenças nas coisas deste mundo e mais além, de forma mais específica, assim talhando conceitos ao mesmo tempo gerais e mais circunscritos historicamente. Uma concepção mais aberta do direito, sempre pensado a partir do contraste com sua expressão ocidental moderna, poderia ter caminhado na mesma direção. Se "contrastar" o mundo moderno com as sociedades anteriores serve realmente como estratégia na construção de todos os seus "tipos ideais" - conceitos "puros" que descritivamente exageram certos aspectos empíricos da realidade, sendo nesse sentido fictícios (Weber, 1921-1922:124) -, aí cobra ela preço mais evidente, amenizado ao menos no que tange a outros conceitos, como os de "dominação", que parecem mais saturados de historicidade autônoma.

Tomemos outro exemplo, o da sexualidade, questão crucial sempre nos escritos de Weber, e da reprodução das gerações, contribuição única e ainda pouco explorada em seu pensamento (ver, porém, Collins, 1986: cap. 11). Se a família nuclear (ou conjugal) é muito característica talvez da maioria das formações sociais, nem de longe é ela universal ou toma mais importância que outros elementos de organização social. Muitos povos privilegiam a "casa masculina" - onde se congregam guerreiros maduros e jovens - antes que o laço entre homem e mulher, ou formas de família em que o par conjugal não tem centralidade, sem falar nas formas patriarcais em que uma família que inclui muitos agregados, escravos entre eles por vezes, se articula sob uma forma de dominação tradicional (Weber, 1921-1922:212-222; 1923:23-64). Assim, é de diversas maneiras que o sexo e a reprodução das gerações têm lugar, sem que se precise supor sequer que a família seria seu eixo fundamental (o que escapasse disso surpreendendo por exemplo, de modo profundo, a outro grande comparativista, posterior a Weber, a saber, Lévi-Strauss, 1969).

Ora, Weber, por outro lado, embora detalhada e historicamente tenha tratado desses diversos temas, não os desenha exatamente em termos de questões gerais. No máximo os singulariza de maneira sistemática em seus estudos sobre a religião, nos quais, em termos das esferas de valor da própria modernidade (logo as multiplicando e emprestando-lhes terminologia moderna), aponta para as "direções" de "rejeição 
do mundo" por parte de atores individuais, multidimensionalmente (Weber, 1920b). Isso é, de certa forma e dentro dos limites assinalados, o contrário do que vimos anteriormente em Marx e Engels, quando consideraram a produção e reprodução da vida como as questões sociais existenciais fundamentais que as formações sociais têm de resolver. Portanto, cada uma dessas abordagens nos oferece um dos elementos da solução, porém lhes falta o outro. Para encaminhar assim inicialmente o problema, é mister reconhecer as questões existenciais em suas quatro dimensões básicas, bem como admitir que foram resolvidas de maneiras específicas e distintas ao longo da história social humana $^{8}$, com destaque para a modernidade, o estágio atual de evolução da espécie (multilinear ela mesma, deve-se mencionar de passagem), cujas respostas àquelas questões precisam ser relativizadas. Não nos interessa apenas essa generalidade, nem uma concepção estática do problema, mas sim como se coloca historicamente de maneira particular, bem como dinâmica.

Cada uma dessas questões existenciais, nos planos individual e coletivo, evolui de sua própria maneira, pondo problemas e demandando respostas relativas a seus próprios requerimentos. Mas, por outro lado, cada uma delas sofre a influência e influencia o modo de se colocarem e resolverem as outras questões. Como produzir depende de como se realiza a reprodução, de como se articula o universo hermenêuticosimbólico e de como se distribui e organiza o poder, afetando também a forma de se articularem e desdobrarem essas outras questões existenciais. O mesmo é verdadeiro se as relacionamos com os processos produtivos e entre si. Agregue-se que isso varia não apenas em cada civilização e formação social, mas igualmente ao longo de suas histórias específicas. Nenhuma dessas questões e suas resoluções é capaz de totalmente condicionar as outras, há certo grau de indeterminação na forma como evoluem e como se relacionam umas com as outras, uma vez que as respostas, ademais e sobretudo, não se põem por si mesmas. Antes se colocam essas questões para indivíduos e coletividades e somente encontram resposta por meio de sua ação e de seu movimento, que são sempre criativos, abertos ao futuro, embora a maneira como foram enfrentadas no passado perdurem em memórias de diversos tipos (em práticas, instituições, imaginários e aspectos materiais da vida social), as quais são o ponto de partida parcial para novas soluções.

Como se dá esse entrelaçamento e influência mútua, o peso de cada sistema social que se articula para enfrentar cada questão sobre os outros 
sistemas sociais que se constituíram para enfrentar outras delas, causalmente, não pode ser determinado a priori e genericamente. Cada civilização ou formação social, em cada período de seu desenvolvimento, tem nesse sentido suas especificidades. Isso quer dizer que exercícios deterministas ou a tentativa de estabelecer leis causais gerais estão fadados ao fracasso. Isso não implica que possamos somente chegar a generalizações empíricas a partir de casos concretos. Se a ideia de leis gerais do desenvolvimento social se mostra falaz também em relação a essas questões, isso não impede que reconheçamos que civilizações e formações sociais podem ter os processos de desenvolvimento vinculados a elas estabelecidos analítica e causalmente de maneira bastante geral. É preciso verificar, para cada caso, como isso se realiza, o que, por exemplo, Marx (1867:21-24; 1894:parte III, caps. 13-15) fez no que tange ao desenvolvimento do capitalismo através da identificação das tendências gerais da acumulação capitalista, que levariam esse modo de produção a impasses insuperáveis, estivesse de fato certo ou não em suas conclusões específicas (trata-se da famosa questão da "queda tendencial da taxa de lucro", além da concentração de capital nas mãos de poucos expropriadores, com uma enorme classe trabalhadora do lado oposto).

Se é possível, além disso, desvendar tendências mais gerais dentro de processos amplos mas particulares a cada civilização, como a racionalização de cunho instrumental que Weber percebia como se desdobrando inexoravelmente no ocidente, é também algo que somente a pesquisa de cada caso que se queira considerar pode responder. Ter isso em mente criticamente e ao mesmo tempo estarmos preparados para reconhecer sua efetividade na modernidade é o que, fundamentalmente, nos permite escapar da hipostasiação da ideia de que a vida social se estrutura por meio de sistemas econômicos, políticos e culturais ou "ideológicos" (sempre com um etc. que permite adicionar outros elementos ad hoc, como talvez a sexualidade ou o direito), seja essa estruturação vista como universal ou como fruto de um processo de diferenciação (como em Parsons, 1971).

\section{QUESTÕES EXISTENCIAIS, TENDÊNCIAS DE DESENVOLVIMENTO, GIROS MODERNIZADORES}

Pode-se dizer, de acordo com o que foi argumentado ao fim da seção anterior, que é contingente a resposta às questões existenciais aí apresentadas, mesmo que com reservas? Isso estaria em linha com a quase 
totalidade das discussões que se encontram nas Ciências Sociais contemporâneas - com exceção do que é o caso com o capitalismo, ao menos na visão de autores marxistas ou fortemente influenciados por essa perspectiva, surgindo seus processos de expansão como inexoráveis. Cada indivíduo e cada coletividade responderiam assim a essas questões, a cada momento, afora no que se refere então ao capitalismo, em princípio de maneira bastante imprevisível. Contudo, conquanto saibamos que há variação nessas respostas, é evidente que há padrões em cada civilização e formação social, que se reproduzem de maneira mais ou menos regular e homogênea. Não caberia aqui readentrar o debate sobre "ação e estrutura", que tratei em várias outras ocasiões, tampouco discutir com pormenores o tema da evolução social, que dificilmente se deixaria aprisionar hoje por visões unilineares, mas que nem por isso deveria ser descartada (Domingues, 1995, 1999 e 2014).

Há continuidades até certo ponto na forma de responder às questões existenciais, heterogêneas entre si muitas vezes, de modo geral apresentando certa coesão, especialmente quando uma civilização se constitui e elas se influenciam de maneira intensa. Isso empresta certo grau de coerência a uma civilização, embora em geral, ao expandir-se, quando o faz, essa coerência tenda a se perder, ao mesclarem-se seus padrões civilizacionais com aqueles oriundos de outras civilizações, que organizam a resposta àquelas questões de maneira distinta, dando origem assim a formações sociais que se podem definir como híbridas ou algo semelhante. Deve-se sublinhar, no entanto, que, se há continuidades na passagem de uma civilização a outra, há também descontinuidades fortes, muitas vezes rupturas radicais. Além disso, dentro de cada civilização e cada formação social encontramos processos que se reiteram. Mediante eles inclusive, de forma intencional ou não, mantém-se a identidade desses tipos de sistemas sociais, embora recorrer ao conceito de "estrutura" em sentido ontológico para resolver esse tema teórico não seja a melhor solução, valendo antes teorizar a reprodução das práticas, das instituições e dos imaginários dos indivíduos e das coletividades no que diz respeito à resposta àquelas questões existenciais, seja como for que se organizem.

De modo a avançar teoricamente, concentremo-nos agora na discussão acerca de como essas questões se desdobram em uma civilização específica, nomeadamente, a modernidade. Não tenciono aqui decidir empiricamente ou sequer apresentar de forma sistemática teorias de médio alcance que deem conta de qualquer uma delas. Não resta dúvida 
de que isso é importante, embora seja também essencial compreender suas imbricações, em seus contextos originais europeus e ao expandir-se, com suas próprias tendências de desenvolvimento, e converter-se em uma modernidade global heterogênea, articulada de forma multidimensional e multitendencial (Domingues, 2012 e 2014). No que se segue, quero apenas delinear, primeiro, o tema de maneira geral e então pensar, indicativamente tanto em termos do desenvolvimento da modernidade - ou seja, de acordo com o que se pode definir como suas tendências de desenvolvimento - quanto em relação a como se dá sua imbricação, como resposta à questão em seus próprios desdobramentos entrelaçados. Em suma, minha meta é propedêutica. Tendo reposto o tema das dimensões da vida social buscando uma solução analítica que vá além de Marx, Engels e Weber, quero agora delinear uma estratégia para avançar em termos de seus desdobramentos sistemáticos nos quadros de uma renovada teoria da modernidade.

A modernidade tem sido caracterizada por elementos institucionais que comparecem, de uma maneira ou de outra, às obras de diversos autores. A título de exemplo, a seguir elenco teses e autores bastante centrais na literatura sociológica, os quais ajudam a situar os temas em tela (ver também, Domingues, 1999, 2002 e 2009).

Há teses bastante gerais, como as da racionalização e do surgimento de esferas diferenciadas, em Weber, ou da divisão do trabalho e do surgimento de uma nova forma, "orgânica", de solidariedade, em Durkheim, com Parsons já enfatizando a diferenciação social de modo mais geral, Habermas seguindo na mesma senda, mas combinando-a com teses amplas sobre a racionalização, neste caso tanto instrumental quanto comunicativa. Há casos intermediários, como o de Marx, em que o capitalismo, uma esfera institucional específica, é discutido em pormenores conceituais, ao mesmo tempo servindo como o elemento que define e causalmente influencia todas as outras esferas da modernidade. Ou o de Elias, calcado nos processos de monopolização do poder, controle das pulsões e pacificação, discretos, mas relacionados e decisivos para toda a vida social. Giddens, por outro lado, buscou uma maneira multidimensional de lidar com o tema, o capitalismo e a industrialização, a vigilância estatal e a industrialização da guerra singularizados como seus eixos institucionais fundamentais, embora ele aduza vários outros ao longo de sua argumentação, que tem ainda nos "desencaixes" de relações sociais de coordenadas mais estáveis e limitadas no tempo-espaço um elemento mais geral do desenvolvimento da moder- 
nidade. Embora formas de consciência, em Durkheim e Weber, Parsons e Habermas, bem como Marx, estejam presentes em todas essas discussões e o último enfatize o papel da ideologia, o tema do imaginário - isto é, de como as pessoas concebem a modernidade e nela se concebem ou os valores que lhes orientam - tem tido menos ênfase analítica dentro da Sociologia. Eisenstadt de certo modo buscou uma saída para as teorias da modernização em parte por meio da ênfase na "cultura", ao passo que Castoriadis, criticando o marxismo, iluminou a contingência da história e sua criatividade, mediante o conceito de "imaginário radical" (ainda que em sua versão seja este muito individualista).

Todos esses autores e vários outros - por vezes em nível de generalidade conceitual mais baixo - tratam essas instituições ou imaginários, quando o fazem, em termos de uma tendência a se desenvolverem, se desdobrarem, dentro da modernidade. Encontramos isso, por exemplo, nas teorias da modernização liberais do século XX (ver Knöbl, 2001), assim como nas interpretações marxistas do mesmo período (ver Aricó, 1976-1977; Jay, 1986, respectivamente para o marxismo militante e para o dito "ocidental"). Mas também, a menos que adotem de fato uma visão descontinuísta da história, como Giddens, que mantém de todo modo aquela primeira perspectiva, buscam assinalar como os elementos que caracterizam a modernidade emergiram em formações sociais anteriores, seja de maneira mais contingente historicamente, seja como resultado de evoluções até mesmo unilineares da espécie humana. Em suma, estamos aí dentro do universo do que se pode caracterizar como conceitos-tendência; trocando em miúdos, conceitos que buscam compreender desdobramentos mais ou menos contingentes ou inexoráveis dentro deste tipo de civilização ou mesmo em termos de sua gênese em um processo histórico muito mais dilatado.

A Sociologia e as Ciências Sociais contemporâneas, de modo mais geral, parecem desinteressadas desse tipo de questão, mas ele segue retornando pela porta dos fundos, uma vez que a maioria dos conceitos que elas continuam a utilizar para analisar a vida social, seja hoje, seja anteriormente, são exatamente aqueles que, um dia, foram tratados como fruto de processos de desenvolvimento que levaram à modernidade e seguem se desdobrando dentro dela, mais ou menos modificados. Sem tematizá-los, apenas os hipostasiam, assim como hipostasiam a resposta às questões existenciais que examinamos diretamente na primeira parte deste artigo. Isto é, tratam fenômenos históricos 
como o capitalismo, o Estado moderno ou a família como dados, reconheçam ou não que correspondem a formas históricas, sem de todo modo analisar seus fundamentos, deste modo perdendo parte do que são de fato os processos e mecanismos mais profundos com que se constituem e se transformam. Isso é ainda mais radical nas suposições de que a "sociedade" (em si conceito já hipostasiado e reificado) possui as dimensões da economia, da política, da cultura etc. Ou então, o que me parece uma alternativa desesperada para escapar dos dilemas do determinismo e da necessidade histórica, os pesquisadores nas diversas Ciências Sociais lidam com essas dimensões e aqueles sistemas mais específicos de maneira tão contingente que beiram o nominalismo. De toda maneira, deixam assim de lado o significado geral desses conceitos e o desdobramento dinâmico e estendido daqueles processos (embora, é claro, os relatos pós-modernos tendam a fazer exatamente o contrário do que prometem, ao evocarem grandes eras e tendências poderosas de desenvolvimento, como o fez Lyortad, 1979).

Para adequadamente capturar as respostas àquelas questões sociais existenciais, é necessário, todavia, analisar a gênese de suas respostas em civilizações e formações sociais específicas, bem como sua reprodução, sempre implicando certo grau de mudança, e possível transformação radical. Ademais, é preciso ver como isso ocorre em termos da autonomia relativa das respostas àquelas questões, bem como no que se refere a seus entrelaçamentos e influências causais mútuas. Isso deve ser feito em face de análises empíricas, ainda que generalizantes, mas é preciso sobretudo identificar analiticamente os mecanismos que presidem a esses processos. Chamei-os de gerativos, reiterativos e transformativos, em termos de uma construção analítica mediante a qual esses conceitos-tendência específicos podem ser articulados como soluções dinâmicas daquelas questões (Domingues, 2015).

Destarte, duas tarefas nos esperam, de modo a retomar discussões que me parecem cruciais nas Ciências Sociais e na Sociologia, mas também nos quadros de uma teoria crítica renovada, que busque não apenas entender a história de modo geral e a gênese da modernidade e sua reprodução, mas também os processos e mecanismos que podem levar para além dela ${ }^{9}$. Por um lado, trata-se de uma análise histórica e da sociologia histórica. O melhor é que seja orientada por conceitos analíticos gerais (alternativamente por tipos ideais), debruce-se sobre a modernidade ou sobre outras civilizações. Por outro, cumpre examinar como essas supostas tendências de desenvolvimento, inclusive no pla- 
no da modernidade, se desdobram, a partir das mesmas categorias analíticas usadas para pensar sua gênese (na verdade estas encontrando-se na dependência do que o pesquisador identificar em sua análise dentro de uma civilização como os elementos mais importantes, pois os processos que nos fazem transitar de uma civilização a outra são demasiado complexos e multifacetados para que se possa abordar tudo o que ocorre historicamente, sem delimitação e seleção de variáveis causalmente destacadas).

Assim, Estado moderno, capitalismo, família nuclear no ocidente etc. mas também sua projeção e desenvolvimentos específicos em outras regiões do mundo, em seu entrelaçamento e hibridização com elementos oriundos de outras civilizações (ver Domingues, 2012) - podem ser analisados de forma dinâmica e mais aprofundada. Deve-se sublinhar que o entrelaçamento, com intensidade e vetores variáveis, dos desdobramentos de cada uma das questões existenciais, articuladas muitas vezes e crescentemente, no contexto de uma complexificação da vida social, por sistemas sociais concretos eles mesmos múltiplos e complexos, acrescenta um desafio enorme à pesquisa. As redes causais se adensam e as influências múltiplas fazem-se multifacetadas, tornando-se, portanto, mais difícil discernir o que começa onde e qual seu peso específico no desdobramento dos processos sociais de cada formação social - em seus vários planos "escalares" (local, nacional, regional, planetário) - e da civilização moderna global hoje de modo geral.

Isso se refere ao que é possível definir como a metodologia de análise das questões sociais existenciais e sua organização em termos de dimensões e sistemas sociais específicos, em particular na modernidade, mas não somente nela. Vejamos agora o que isso pode significar em termos mais substantivos.

Em primeiro lugar, que fazer com a tradicional divisão entre economia e política? Ela tem como extensão a necessidade de introduzir a cultura como outra dimensão - ou, em teorias mais sofisticadas, como a de Habermas (1981), um "mundo da vida" em que radicam "cultura", "instituições" e "personalidade" -, com outras dimensões aduzidas em diferentes teorias. Por um lado, aquela divisão é real e remete à separação que a modernidade introduziu entre a esfera da "sociedade civil", cujos fundamentos estariam, por um lado, na economia, mas que incluía também a família, a imprensa, eventualmente as igrejas e ou- 
tras entidades, e, por outro, Estado, o que na complexificação do marxismo por Gramsci acabou levando a um argumento curioso, quase invertido, segundo o qual aquela esfera formaria parte de um "Estado ampliado" (ver Cohen e Arato, 1992, para a evolução do conceito).

Aquela divisão não é meramente fictícia (como Poulantzas por vezes sugere, também em versão mais sutil da dimensão política na teoria marxista). Ela de fato estrutura o conjunto da vida social, em especial pela separação entre público e privado, mas tem por outro lado um forte elemento ideológico (no sentido de ocultar a realidade em função dos interesses de classe burgueses, como sugere), porquanto escamoteie a interpenetração efetiva entre essas duas esferas e o poder e penetração do estado sobre a "sociedade civil". Soma-se a isso que, embora formalmente menos separado da "sociedade", jamais o Estado foi outrora capaz de controlá-la e moldá-la tão intensamente, passando de uma relação meramente "despótica" (capacidade de repressão) em civilizações anteriores a um "poder infraestrutural" significativo, combinado com agentes da própria "sociedade" externa a ele, mediante uma capacidade normativa-gerativa não meramente repressora e violenta (ver Giddens, 1985: em especial cap. 7; Mann, 1986 e 1993; em ambos a influência de Foucault é explícita).

É evidente que nem a política nem a economia se desenvolvem separadamente. Ao contrário, encontram-se entrelaçadas, ainda que cada uma possua sua própria dinâmica (ou, como dizem os alemães, Eigendynamic), que se desdobra a partir de suas contradições, projetos, consequências não premeditadas e daí por diante. O mesmo se poderia dizer da "cultura", expressão bastante estranha, a rigor, uma vez que todos os sistemas sociais - ou que aparecem como política e economia têm como elemento constitutivo uma dimensão hermenêutica, tecida simbolicamente, inescapável, mesmo quando seu sentido for, como sugerem Weber e os frankfurtianos, seu esvaziamento e ressecamento (ver, para uma revisão geral, Habermas, 1981, que leva este argumento a seu extremo no que tange aos sistemas supostamente "autorregulados"). Note-se que alguns autores, como Castells (1996), chegam a dizer que hoje a "cultura" estaria se autonomizando. Ocorre que, por mais que empiricamente possa haver elementos interessantes em sua análise, ele peca por ter seu ponto de partida na reificação e na hipostasiação desse conceito, aparentemente óbvio em sua faticidade, o qual teria, contudo, que ser desde o início problematizado, com todas as consequências que isso implica. 
Se nos dirigimos a sistemas ainda mais específicos, como o Estado, a família, o mercado etc., essas questões se fazem ainda mais complicadas, porém claramente necessitando de revisão. Se falamos do desenvolvimento da política, de que falamos? Do "Estado"? Ou, um pouco mais amplamente, da "sociedade civil"? Ou na verdade nos referimos a um conjunto de práticas, que atravessam ambas essas construções sociais modernas - imaginárias mas também muito reais, pois de fato organizam, por meio em larga de medida de instituições, o conjunto das atividades sociais -, sem deter-se nelas? Isto é, falamos delas somente ou a família e a amizade, o esporte, a ciência, a religião e tantos outros sistemas têm de ser pensados não apenas como parte da "sociedade" ("civil" ou como se a queira definir), como percucientemente sugeriu Gramsci, mas como estando todos diretamente relacionados, de maneiras próprias, à distribuição do poder? Parece-me evidente, se se leva em conta que as questões sociais existenciais são temas gerais e abertos, que as respostas a seus requerimentos não podem ser reduzidas a um ou dois sistemas sociais concretos, senão que está disseminada por vários deles, no que tange tanto a problemas gerais quanto a outros mais específicos (quem vota, por exemplo, ao mesmo tempo em que o tipo de sexualidade que é autorizada e estimulada também se constitui em objeto de definição mediante relações de poder, no que se refere a outros sistemas e agentes - subjetividades coletivas, ou seja, homens, mulheres, padres, capitalistas, feministas etc., como de resto estas últimas foram pioneiras em enfatizar com o famoso "o pessoal é político").

O mesmo se pode afirmar do capitalismo. Trata-se de sistema meramente econômico? Ou deve ser desde o início definido em termos multidimensionais? Se em seu cerne se encontram as relações de produção e consumo, em sua imbricação com a natureza, mediados pela circulação de mercadorias, não é possível entendê-lo como separado da política, com o direito cumprindo papel de mediação entre estas e outras "dimensões" e sistemas. O próprio Marx chamou a atenção para isso, ainda que em $O$ Capital perseguisse estratégia mais circunscrita analítica e concretamente à economia. Foi sobretudo Polanyi (1944), todavia, quem sublinhou, com efeito de modo exagerado, que o Estado liberal teria efetivamente constituído o mercado ou ao menos o desencaixado do conjunto das relações sociais a partir de um projeto comandado politicamente por forças liberais. Seria absurdo pensar também que a "cultura" - ou a "ideologia", caso assim se prefira - se põe como dimensão externa à economia. Este é equívoco em que incorre Habermas, ainda que de modo geral não os marxistas, Marx ele mesmo enfatizando em especial 
o papel do "fetichismo da mercadoria", do dinheiro e do próprio capital como construções simbólicas opacas. Em contrapartida, subordinam causalmente a dimensão hermenêutico-simbólica à dinâmica da economia, roubando-a destarte em larga medida de sua própria dinâmica, nem que isso se remeta, na melhor das hipóteses, à "determinação em última instância". Não deixa de ser curioso ver como Castells, vindo do marxismo, tentou saltar na direção oposta, incorrendo em larga medida em equívoco simétrico ao que anteriormente cometia ${ }^{10}$.

Assim, uma série de distintas possibilidades se abre. Uma delas é tratar as questões existenciais e as diversas respostas a elas historicamente, reconstruindo sua evolução, no que diz respeito também à modernidade, de modo geral e nesse caso particular dando atenção aos processos que levaram a elas e se desdobram daí por diante. Não há que supor nesse sentido nenhuma teleologia, uma vez que, embora haja sem dúvida elementos fortes do que se convencionou chamar de "dependência de trajetória" nesses processos, com o ponto de partida influenciando os desdobramentos seguintes, a criatividade social sempre intervém e lhes empresta por vezes direções inesperadas. É o que enfatizaram autores que adotaram pontos de vista descontinuístas (como Gellner, Giddens e Mann). Foi também o que tentei capturar, do ponto de vista da teoria da subjetividade coletiva, em termos do conceito de giros episódicos, que na modernidade se convertem em giros modernizadores, tecendo assim o desenvolvimento social em termos intencionais ou como consequências não intencionais da ação individual e do movimento coletivo (Domingues, 1999:cap. 4, 2012).

Estratégias comparativas, como a de Weber, podem ser aplicadas com o fito de abrir o foco da análise, dentro dos quadros de uma civilização, bem como entre elas. São assim possíveis construções analíticas mais sistemáticas, quer no que tange à discussão das questões sociais existenciais - nos quadros de exposição mais abstrata, mas nem tanto, uma vez que esses conceitos se implicam mutuamente-, ou no que se refere a uma civilização específica, a modernidade no caso que propus mais diretamente considerar neste texto. Tanto um ponto de vista dito sincrônico, estrutural-descritivo, quanto outro, mais complexo, diacrôni$\mathrm{co}$, que capta as tendências de desdobramento das respostas àquelas questões, pode ser adotado, na verdade se pondo essas duas possibilidades de modo complementar. Nesse passo, os três tipos de mecanismos - gerativos, reiterativos e transformativos - mencionados anteriormente são fundamentais, de maneira a não permitir que a análise deslize para a mera descrição, mesmo que organizada por conceitos, 
cujo poder teórico termina por ser limitado. É fundamental explicar como os processos se desdobram.

Por um lado, vale analisar as tendências com certo grau de isolamento, ao menos inicialmente, mas isso tem de ser depois corrigido mediante uma análise mais ampla que focalize o impacto - causal - das respostas às questões umas sobre as outras. Nesse sentido, não se trata de tarefa nada fácil, embora não careça ser levada ao paroxismo de pensar-se que somente a visão da totalidade poderia solucionar o problema, estratégias mais discretas e intermediárias usualmente se mostrando mais factíveis, sem que a vertigem da compreensão absoluta leve tragicamente à paralisia.

Enfim, é preciso considerar que, se tomamos os processos de surgimento, desdobramento e evolução da vida social utilizando-nos de conceitos-tendência articulados com esse fim, combinando a construção de categorias como política e economia, Estado e sociedade civil, capitalismo e neopatrimonialismo, família nuclear e patriarquia, nação e cidadania, etnicidade e racismo, entre outros, que podem e devem avançar para além do plano descritivo, com a explicação dos processos por meio de mecanismos, isso apenas preliminarmente pode ser feito considerando-os em seu estado de pureza conceitual e histórica. No solo mesmo de sua emergência e desenvolvimento iniciais, a Europa, eles já se imbricaram concretamente com formas prévias de resposta às questões existenciais. Isso muitas vezes perdura longamente, os giros modernizadores específicos que se realizam emprestando à modernidade características bastante particulares em cada local ou país nessa região. Ao ampliarmos o foco e nos debruçarmos sobre a modernidade global, que resultou da expansão da civilização moderna desde a Europa, essa imbricação se torna verdadeira hibridização, uma vez que incorpora outros elementos civilizacionais através do planeta. Isso significa que os giros modernizadores são híbridos eles também e que as tendências de desenvolvimento se fazem ainda mais complexas, mas de modo algum impossíveis de resolver. Quer dizer, de possível resolução desde que se ponha a interrogação sobre as questões existenciais e o desenvolvimento das respostas a elas de modo sistemático.

\section{PALAVRAS FINAIS}

Chegamos assim ao fim de nosso percurso conceitual, que tratou de temas na verdade quase intratáveis nas Ciências Sociais. Desde o materialismo marxista a demandas de que elas se articulem de maneira 
multidimensional, passando por alguns tipos de abordagem de cunho culturalista, hoje de resto muito disseminado, uma indagação tem se posto, aberta ou veladamente, quanto à relação entre os diversos aspectos da vida social, que busquei focalizar a partir de quatro questões sociais existenciais fundamentais. Poder-se-ia quase dizer que se referem a verdadeiras "condições de possibilidade" da existência da espécie humana e dos sistemas sociais em que se organizam, se se quiser recorrer à linguagem kantiana, mas com a clareza de que são práticas humanas concretas o que se encontra em questão, não da constituição metafísica do sujeito ou da realidade em geral, cujo resultado de certo modo é dado de antemão, carecendo ser simplesmente explicado ${ }^{11}$.

Trata-se, em vez disso, dos temas da produção e reprodução da espécie, da distribuição do poder e da criação de sentido, com suas direções indeterminadas e inclusive falibilidade histórica. Na medida em que o "materialismo histórico" se ossificou e desde que o que se convencionou chamar de "giro linguístico" nas Ciências Sociais se verificou, essa discussão perdeu seu rumo. Ou simplesmente se afirma a importância da materialidade da vida humana e de sua causalidade social, sem conseguir progredir conceitualmente, ou se leva ao extremo a ideia de que é na esfera da linguagem ou do "discurso" que se situam os processos e impulsos causais mais importantes, com o que os avanços efetivamente alcançados nas últimas décadas ficam severamente prejudicados. Paralelamente, alguns preferem dar ênfase ao poder, seja uni ou multidimensionalmente, certas abordagens o absolutizando em termos ontológicos e explicativos, ao passo que a reprodução da espécie e a sexualidade ou se mantiveram no âmbito de formas variadas de psicanálise (ou de seus críticos) ou deslizaram para a mera descrição empírica.

Este artigo ensaiou, portanto, lançar-se em direção pouco comum hoje, retomando discussões cruciais e muito gerais, que o marxismo originalmente propôs e às quais as disciplinas das Ciências Sociais, inclusive e com destaque a Sociologia, outrora buscaram dar continuidade. Ele o faz, além de concentrar-se naquelas questões existenciais, retomando outros temas que saíram do radar dos cientistas sociais nas últimas décadas, em que vem imperando a ideia de contingência como elemento inescapável da vida social e da histórica, a despeito da expansão da modernidade - com ares de absoluta necessidade, quase se assemelhando à expansão da racionalidade em termos weberianos e de seus tributários -, em seu entrelaçamento com outros elementos sociais ${ }^{12}$. Em outros contextos tentei argumentar a favor de uma sociologia da 
modernidade global, como civilização expansiva e agora visivelmente heterogênea, como um dos caminhos pelos quais a Sociologia pode e deve recobrar seus impulsos teóricos, neste momento abafados.

Ademais, combinei essa sugestão com uma demanda, exatamente por essa via, de renovação da teoria crítica. Os conceitos-tendência que se propõem a compreender a modernidade em sua dinâmica de gênese, desenvolvimento e possível superação são imprescindíveis para que passemos de um plano meramente descritivo ou até mesmo restritamente interpretativo-conceitual a outro mais analítico e explicativo. Esse caminho seria, ao tentar divisar janelas de possibilidade da mudança social, a base para uma ampliação da crítica imanente, além daquilo que agentes de vária natureza, com destaque para os movimentos sociais, e intuições morais concretas seguem energizando em direção emancipadora em nosso mundo.

Se isso depende de correntes mais amplas e profundas na vida social, representadas por esses agentes e intuições, na luta contra a exploração e a opressão, nem por isso devem as Ciências Sociais deixar de contribuir nessa direção. Mas, para fazê-lo, é importante enfrentar novamente os problemas fundamentais da teoria social, entre os quais se encontram o que aqui denominei de questões sociais existenciais. Elas nos permitem melhor situar o momento presente conceitualmente e abrem-nos as portas para uma melhor compreensão dos sistemas sociais em que se organizam na modernidade. Ressaltam sua contingência e variação, mas também imbricação mútua, bem como seus níveis variados de necessidade e coesão, suas múltiplas tendências de desenvolvimento, gerativo, reiterativo e inexorável superação, logo, nessa conjunção, sua historicidade. Se não é garantido sucesso na identificação de mecanismos que podem nos levar além da modernidade, pois ademais isso depende de como eles efetivamente se desdobram hoje, é na pior das hipóteses relevante que de novo encaremos esse tipo de questão, que pode não ser existencial no sentido utilizado neste texto, mas sobre cuja importância não deveriam restar dúvidas.

(Recebido para publicação em abril de 2015)

(Reapresentado em agosto de 2015)

(Aprovado em setembro de 2015) 


\section{Questões Sociais Existenciais, Tendências de Desenvolvimento e Modernidade}

\section{NOTAS}

1. Tampouco resulta pôr a "cultura" como princípio unificador, como faz Parsons (1951:167-169 e passim), com um sistema de valores que se especifica normativamente em cada subsistema, embora alguns deles possam exibir valores e normas que dele divergem.

2. Tese repetida bem mais tarde por Engels (1884:27) no livro que utiliza as notas de Marx sobre a obra de Morgan e no qual a família tem papel central.

3. Em texto mais recente, sobre a modernidade especificamente, Wagner (2008:4-5) sugeriu tratar alguns de seus aspectos por meio da noção de "problemáticas". Ao que parece, embora isso não esteja totalmente claro em sua argumentação, buscava escapar do mesmo tipo de problema identificado neste artigo e avançar talvez em direção semelhante.

4. Isso inclui a relação entre "natureza" e "cultura", tal qual formulada no ocidente, a qual não encontra correspondência em outras civilizações, talvez genericamente compreensível mediante conceitos mais gerais como os de "identificação" e "relação" (Descola, 2005). Estas são questões, conceituais e práticas, inevitáveis individual e socialmente, não sendo porém a melhor solução para sua interpretação o neokantianismo estruturalista, combinatório (mesmo se quer manter-se conectado à empiria e às práticas). Trata-se, provavelmente, na verdade de finitas possibilidades de responder praticamente às demandas da vida social, o que gera aquilo que parecem ser estruturantes invariantes do espírito humano (devendo-se também duvidar de se são tão rígidas e excludentes as respostas a esta e a outras questões, como sugere Descola). Enfim, aproveite-se o ensejo para observar que a noção de "cultura" é amiúde utilizada de maneira extremante inespecífica e abrangente na antropologia.

5. A "alocação autoritativa de valores" (da teoria dos sistemas de Easton, 1965:50) deve ser vista como mero subconjunto da distribuição de poder e dela dependente (sem que se deva supor a universalidade dos sistemas políticos); e é também apenas parcialmente "autoritativa", uma vez que pode ser profundamente conflituosa. Essa definição ecoa a da "economia", de corte neoclássico, como alocação de recursos "escassos" face à demanda, especialmente via mercado, sinais de preços e equilíbrio (Robbins, 1932:cap. 1 e 45-46), a qual por seu turno secundariza a questão central do intercâmbio material com a natureza.

6. Há uma relação entre as dimensões mais gerais dos sistemas sociais, que defini em outras ocasiões como simbólico-hermenêutica, material, do poder e espaço-temporal, mas elas são efetivamente analíticas gerais na construção do conceito de subjetividade coletiva como tipo geral de sistema social (Domingues, 1995), ao passo que as questões existenciais se referem aos requerimentos da existência da espécie humana enquanto tal, embora os sistemas nos quais se organiza e mediante os quais responde àquelas questões sejam travejados por aquela multidimensionalidade básica.

7. Embora não soe plausível a tese - como em Tenbruck (1980) - de que a religião era predominante nas concepções multifacetadas de Weber, nas quais política e sexualidade - teórica e praticamente - despontam visivelmente como cruciais (a economia aparecendo, curiosamente, sempre de modo pouco criativo em seus escritos, o capitalismo liberal tomado como dado, bem como a metodologia individualista). 


\section{José Maurício Domingues}

8. Por "civilização" entendo um tipo de sistema social muito abrangente, que se transforma ao longo do tempo, mas mantém-se em larga medida idêntico a si mesmo, com respostas a cada uma daquelas questões de modo multidimensional através de sistemas sociais específicos. A modernidade seria uma delas, com suas práticas, instituições, relações com a natureza e imaginários. Por "formação social" entendo um tipo de sistema social mais específico, em que aquelas civilizações se apresentam de forma concreta, muitas vezes ou mesmo de modo geral, mescladas com outras civilizações ou elementos civilizacionais (tendo as civilizações a que pertenciam desaparecido ou se rendido a outra, que os incorpora de forma mais fragmentária). São sempre tecidas pela ação individual e pelo movimento coletivo.

9. Ao passo que Marx e Engels definiram claramente os processos de gênese, desenvolvimento e superação do capitalismo e da modernidade, quaisquer que fossem certas ambiguidades de suas respostas (assentando-se elas sobre classes e subjetividade ou tendências catastrofistas e contradições "estruturais" ou "funcionais"), a teoria crítica foi se concentrando cada vez mais e crescentemente no plano da filosofia e da cultura, ao pensar os processos de desenvolvimento da modernidade, amiúde com viés pessimista, a exemplo de Weber, como no clássico de Adorno e Horkheimer sobre a razão instrumental e o "logocentrismo" (ver Aricó, 1976-1977; Domingues, 2012). Claro, isso remete a problemas reais e aos impasses hodiernos da mudança social radical, mas na teoria social não se deveria levar a paralisia tão longe.

10. Isso não deveria nos impedir de reconhecer, inclusive como autores fora do marxismo argumentam, que o capitalismo tem um grande peso - causal inclusive - no desdobramento global da modernidade, embora não faça sentido pensá-lo como apartado das outras questões existenciais, como tende por exemplo a fazer Chakrabarty (2000).

11. Não consiste em boa solução, por conseguinte, a perspectiva funcionalista em que a realização destas se põe como "pré-requisito" para a reprodução e continuidade dos sistemas sociais, derivando-se facilmente para um problema da "integração" dos sistemas sociais e da "ordem" / "motivação" na versão da questão em Parsons (1951:26-36 e 167-177). As questões existenciais são ao mesmo tempo mais abrangentes e mais contingentes.

12. Embora por seu turno, teoricamente de maneira deficitária e com viés normativo forte, o neomodernismo radical do neoliberalismo reivindique uma tendência empírica e normativa de expansão global dos mercados, que afirma inevitável e necessária, de preferência, mas não absoluta e inexoravelmente, acompanhada da democracia liberal. 
Questões Sociais Existenciais, Tendências de Desenvolvimento e Modernidade

\section{REFERÊNCIAS BIBLIOGRÁFICAS}

ALEXANDER, Jeffrey C. (1988), Action and its Environments. New York, Columbia University Press.

ALTHUSSER, Louis. (1996) [1965], Pour Marx. Paris, La Découverte.

ARICÓ, José. (1976-1977), Nueve Lecciones sobre Economía y Política en el Marxismo. México, Fondo de Cultura Económica; El Colegio de México.

CASTELLS, Manuel. (1996), The Network Society. The Information Age: Economy, Society and Culture, vol. 1. Malden, MA; Oxford, Blackwell.

CASTORIDIS, Cornelius. (1975), L'Institution Imaginaire de la Société. Paris, Seuil.

CHAKRABARTY, Dipesh. (2000), Provincializing Europe: Postcolonial Thought and Historical Difference. Princeton, NJ, Princeton University Press.

COHEN, Jean; ARATO, Andrew. (1992), Civil Society and Political Theory. Cambridge, MA, The MIT Press.

COLLINS, Randall. (1986), Weberian Sociological Theory. Cambridge, Cambridge University Press.

DESCOLA, Phillipe. (2005), Par-delà Nature et Culture. Paris, Gallimard.

DOMINGUES, José Maurício. (1995), Sociological Theory and Collective Subjectivity. Basingstoke, Macmillan Press; New York, Saint Martin's Press/Palgrave.

(1999), Criatividade Social, Subjetividade Coletiva e a Modernidade Brasileira Contemporânea. Rio de Janeiro, ContraCapa.

(2000), "A Cidade: Racionalidade e Liberdade em Max Weber", in Do Ocidente à Modernidade. Intelectuais e Mudança Social. Rio de Janeiro, Civilização Brasileira.

(2002), Interpretando a Modernidade. Imaginário e Instituições. Rio de Janeiro, FGV Editora.

(2008), A América Latina e a Modernidade Contemporânea. Uma Interpretação Sociológica. Belo Horizonte, UFMG Editora.

(2009), "Modernidade e Giros Modernizadores: A América Latina em Perspectiva Comparada", in Teoria Crítica e (Semi)periferia. Belo Horizonte, UFMG Editora.

. (2012), Modernidade Global e Civilização Contemporânea. Para a Renovação da Teoria Crítica. Belo Horizonte, UFMG Editora.

(2014), "Global Modernity, Levels of Analysis and Conceptual Strategies". Social Science Information, vol. 53, no 2, pp. 180-192.

(2015), “Historia, Sociología y Modernidad”. Desarrollo Económico, vol. 55, no 216, pp. 211-225.

EASTON, David. (1965), A Framework for Political Analysis. Englewood Cliffs, NJ, Prentice-Hall.

ENGELS, Fridriech. (1975) [1884], Der Ursprung der Familie, des Privateigentum und des Staats, in K. Marx; F. Engels, Werke. Berlim, Dietz, vol. 21.

GIDDENS, Anthony. (1984), The Constitution of Society. Cambridge, Polity.

DADOS - Revista de Ciências Sociais, Rio de Janeiro, vol. 59, nº 1, 2016 


\section{José Maurício Domingues}

(1985), The Nation State and Violence. Cambridge, Polity.

HABERMAS, Jürgen. (1976), Zur Rekonstruktion historischen Materialismus. Frankfurt am Main, Suhrkamp.

(1981), Theorie des kommunikativen Handelns. Frankfurt am Main, Suhrkamp, vols. $1-2$.

JAY, Martin. (1986), Marxism and Totality: The Adventures of a Concept from Lukács to Habermas. Berkeley e Los Angeles, University of California Press.

KNÖBL, Wolfgang. (2001), Spielräume der Modernisierung. Weilerwist, Velbrück.

LÉVI-STRAUSS, Claude. (1969), “The Family”, in H. L. Shapiro (org.), Man, Culture, and Society. Oxford, Oxford University Press.

LYOTARD, Jean-François. (1979), La Condition Postmoderne: Rapport sur le Savoir. Paris, Minuit.

MANN, Michael. (1986), The Sources of Social Power. A History of Power from the Beginning to A.D. 1760. Cambridge, Cambridge University Press, vol. 1.

(1993), The Sources of Social Power. The Rise of Classes and Nation-States, 1760-1914. Cambridge, Cambridge University Press, vol. 2.

MARX, Karl. (1983) [1857], “Einleitung”, in Ökonomische Manuskripte 1857/58 (Grundrisse), Mega 2/1. Berlim, Dietz.

. (1971) [1859], “Vorwort”, in Zur Kritik der politischen Ökonomie, In: Karl MARX and Friedrich ENGELS, Werke. Berlim, Dietz, vol. 13.

. (1987) [1867], Das Kapital: Kritik der politischen Ökonomie, vol. 1, in MEGA II-5. Berlim, Dietz.

. (1983) [1894], Das Kapital: Kritik der politischen Ökonomie, vol. 3. Berlim, Dietz.

; ENGELS, Friedrich. (1969) [1845], Die deutsche Ideologie, Werke, vol. 3. Berlim, Dietz.

PARSONS, Talcott. (1979) [1951], The Social System. London, Routledge \& Kegan Paul.

(1967), Sociological Theory and Modern Society. New York, Free Press.

(1971), The System of Modern Society. Englewood Cliffs, NJ, Prentice-Hall.

POLANYI, Karl. (2002) [1944], The Great Transformation: The Political and Economic Origins of our Time. Boston, Beacon.

ROBBINS, Lionel. (1932). An Essay on the Nature and Significance of Economic Theory. London, Macmillan.

TENBRUCH, Friedrich H. (1980), "The Problem of Thematic Unity in the Works of Max Weber". British Journal of Sociology, vol. 31, no 3, pp. 313-351.

WAGNER, Peter. (2008), Modernity as Experience and Interpretation: A New Sociology of Modernity. Cambridge, Polity.

WEBER, Max. (1991) [1904], “Die ‘Objekivität' sozialwissenschaftlicher Verursachung in der historischen Kausalbetrachtung", in Schriften zur Wissenschaftslehre. Stuttgart, Philiph Reclam. 


\section{Questões Sociais Existenciais, Tendências de Desenvolvimento e Modernidade}

. (1988) [1920a], "Vorbemerkung", in Die Wirtschaftsethik der Weltreligionen, in Gesammelte Aufsätze zur Religionssociologie, vol. 1. Tübinbgen, J. C. B Mohr (Paul Siebeck).

. (1988) [1920b], Die Wirtschaftsethik der Weltreligionen. Zwischenbetrachtung: Theorie der Stufen und Richtungen religiöser Weltablehnung, in Gesammelte Aufsätze zur Religionssociologie, vol. 1. Tübinbgen, J. C. B Mohr (Paul Siebeck).

. (1980) [1921-1922], Wirtschaft und Gesellshaft. Tübinbgen, J. C. B Mohr (Paul Siebeck).

. (2013) [1923], General Economic History. Masfield Center, CT, Martino. 


\section{RESUMO \\ Questões Sociais Existenciais, Tendências de Desenvolvimento e Modernidade}

O objetivo deste artigo é retornar a alguns temas clássicos, mas hoje muito mal explorados, centrais no passado da sociologia ou daqueles que por ela foram incorporados como seus pais fundadores e hoje a rigor abandonados. Nele se discutem a multidimensionalidade da vida social e as tendências de desenvolvimento que, em particular na modernidade, a impulsionam. Teoricamente esses temas seguem, ou deveriam seguir, sendo decisivos, sem deixar de sê-lo igualmente do ponto de vista da prática social. Enfim, recolocá-los nos permite até certo ponto sugerir uma visão mais complexa e menos etnocêntrica da humanidade em seus aspectos diretamente sociais e, com isso, situar mais precisamente as características diferenciais da própria modernidade.

Palavras-chave: modernidade; questões sociais existenciais; conceitos-tendência; dimensões sociais

\section{ABSTRACT \\ Existential Social Issues, Trends of Development and Modernity}

The goal of this article is to return to some ill-explored classical themes, central in the past of sociology or of those that the discipline incorporated as its founding fathers and that have today been abandoned. The multidimensionality of social life and the trends of development which, particularly in modernity, drove it are discussed. Theoretically these subjects (supposedly) remain decisive, equally from the standpoint of social practice. Ultimately, readdressing them allows us, to a certain extent, to suggest a vision of humanity that is more complex, less ethnocentric, regarding its more directly social aspects and, as a result, more accurately situate the differential characteristics of modernity itself.

Keywords: modernity; existential social issues; trend-concepts; social dimensions 


\section{RÉSUMÉ}

Questions Sociales Existentielles, Tendances de Développement et Modernité

L'objectif de cet article est de reprendre certains thèmes classiques de la sociologie aujourd'hui en désuétude, voire totalement abandonnés, mais centraux dans le passé de la discipline et chez ceux que l'on considère comme ses pères fondateurs. Nous débattrons ici de la multidimensionnalité de la vie sociale et des tendances de développement qui, au sein de la modernité, lui ont donné son élan. En théorie, mais également du point de vue de la pratique sociale, ces thèmes sont toujours - ou du moins devraient l'être - d'actualité. Dans une certaine mesure, les remettre au goût du jour nous permettra de suggérer une vision plus complexe et moins ethnocentrique de l'humanité dans ses aspects les plus directement sociaux, et de situer ainsi plus précisément les caractéristiques différentielles de la modernité elle-même.

Mots-clés: modernité; questions sociales existentielles; concepts-tendance; dimensions sociales

\section{RESUMEN}

\section{Cuestiones Sociales Existenciales, Tendencias de Desarrollo y Modernidad}

El objetivo de este artículo es volver a algunos temas clásicos de la sociología, hoy en desuso o totalmente abandonados, pero centrales en el pasado de la disciplina, particularmente en aquellos que fueron considerados como sus padres fundadores. Se discuten la multidimensionalidad de la vida social y las tendencias de desarrollo que, en el seno de la modernidad, la impulsan. Teóricamente, pero también desde el punto de vista de las prácticas sociales, estos temas siguen, o deberían seguir, siendo centrales. De este modo, recuperarlos nos permite, en cierta medida, sugerir una visión más compleja y menos etnocéntrica de la humanidad en sus aspectos directamente sociales y, con eso, ubicar de forma más precisa las características diferenciales de la propia modernidad.

Palabras clave: modernidad; cuestiones sociales existenciales; conceptos-tendencia; dimensiones sociales 